\title{
PREVENTIVE TRAINING PROGRAMME FOR PATIENTS AFTER ACUTE CORONARY EVENT - CORRELATION BETWEEN SELECTED PARAMETERS AND AGE GROUPS
}

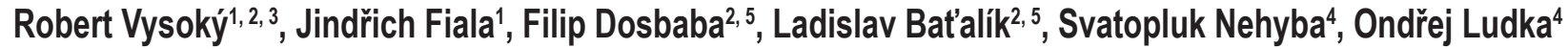 \\ 'Department of Public Health, Faculty of Medicine, Masaryk University, Brno, Czech Republic \\ ${ }^{2}$ Department of Rehabilitation, Faculty Hospital, Brno, Czech Republic \\ ${ }^{3}$ Department of Health Support, Faculty of Sports Studies, Masaryk University, Brno, Czech Republic \\ ${ }^{4}$ Department of Internal Cardiology Medicine, Faculty of Medicine, Masaryk University, Brno, Czech Republic \\ ${ }^{5}$ Cardiac Rehabilitation, Brno, Czech Republic
}

\section{SUMMARY}

Aim: Interventional cardiovascular training programmes provide a prescription of optimal form and safe intensity. They are part of the second phase of cardiovascular rehabilitation which is a key point in the whole tertiary-preventive care for patients with coronary artery disease. The patients are hemodynamically adapted to a normal physical load, their aerobic capacity is gradually increased, and they learn principles of regular aerobic-resistance exercise. The aim of this study is to assess the impact of modified aerobic-resistance exercise on cardiorespiratory indicators in patients after acute coronary event, and evaluate the differences between monitored parameters in different age groups.

Methods: The study was conducted on a group of 106 patients ( $85 \%$ of men) of an average age of $60.4 \pm 10.9$ years, with left ventricular ejection fraction of $57.4 \pm 7.2 \%$. All subjects went through an acute coronary event. The time elapsed between the occurence of a coronary event and the beginning of the training programme was $35 \pm 8$ days. In patients after coronary artery bypass grafting, the time passed was $50 \pm 16$ days on average. All patients received a two-month aerobic-resistance training with a frequency of three times a week. The length of a training unit was set to 100 minutes (out of which 60 minutes were allocated to individual aerobic training).

Results: A significant negative correlation between age and average values of monitored parameters was observed. Even though the values of all parameters are decreasing with increasing age, a shift towards higher values in all parameters occurred after completing the training programme. The study reveals that there are interindividual differences between the parameter values. A significant difference in individual parameters was found between different age groups. The result of the study shows that a given parameter could characterize each age group. Completing the interventional training programme also led to a significant increase of exercise tolerance $(1.8 \pm 0.3 \mathrm{vs} .2 .0 \pm 0.4 \mathrm{~W} / \mathrm{kg} ; p<0.001)$ and of peak oxygen consumption ( $22.8 \pm 4.5$ vs. $25.9 \pm 5.5 \mathrm{ml} / \mathrm{kg} / \mathrm{min}, \mathrm{p}<0.001)$.

Conclusion: Interindividual differences between the parameter values have been identified. This could be helpful in methodological conception of preventive training programmes for patients suffering from cardiovascular disease. The mutual connection between the parameter values and age groups does not relate only to a safer training intensity determination, but also to a more precisely targeted application of different training modalities in order to achieve an optimal final training effect.

Key words: cardiac rehabilitation, secondary prevention, aerobic training, resistance training, aerobic capacity, coronary artery disease, acute coronary event

Address for correspondence: R. Vysoký, Department of Public Health, Faculty of Medicine, Masaryk University, Kamenice 5, 62500 Brno, Czech Republic. E-mail: vysoky.rob@gmail.com

\section{INTRODUCTION}

Despite the existence of modern medical treatments, cardiovascular diseases rank first in the incidence of all diseases worldwide. Prevention plays a crucial role in reduction of such diseases as well as in their treatment and in improving the patient's prognosis, especially due to reduction of relapses and mortality.

Apart from primary and secondary prevention, tertiary prevention should not be neglected as it is continually gaining importance thanks to a constantly increasing number of patients surviving an acute coronary event. For these patients, it is crucial to lower the risk of a new attack as well as to help them return to a good physical condition allowing them to lead a full life.

Physical activity has a positive influence on a number of risk factors of a coronary artery disease. Among the most important ones are dyslipidemia, type 2 diabetes mellitus, hypertension, and physical inactivity. Consequently, adequate amount of physical activity leads to an increased aerobic capacity of the organism which is associated with a reduction in mortality caused by cardiovascular diseases as a result of positive influence of physical activity on the risk factors.

Interventional cardiovascular training programmes provide a prescription of optimal form and safe intensity. They are a part 
of the second phase of cardiovascular rehabilitation programme (CRP) which is a key point in the whole tertiary-preventive care of patients with coronary artery disease. The patients are hemodynamically adapted to a normal physical load, their aerobic capacity is gradually increased, and they learn the principles of regular aerobic-resistance exercise. The third and the fourth phase do no longer take place under the supervision of a physiotherapist. During these final phases, the stabilization of patient's clinical condition and maintaining training habits take place (1-5).

The aim of our study was to evaluate the effect of modified aerobic-resistance training on cardiorespiratory parameters and assess differences between monitored parameters in different age groups of patients after an acute coronary event.

\section{MATERIALS AND METHODS}

\section{Subjects Characteristics}

The study included 106 patients. Their basic characteristics are listed in Table 1 and 2. Patients were 18 years old and older, and met the indication criteria for classification according to the recommended procedures for rehabilitation of patients with cardiovascular disease issued by the Czech Society of Cardiology in 2006 (1).

The acceptance criteria of the study were: an acute coronary event taking place at minimum three weeks before joining the programme, stabilized clinical condition, appropriate medical therapy prescribed, and left ventricular ejection fraction over 50 percent (measured by transthoracic echocardiography prior to the enrollment in the rehabilitation programme).

The exclusion criteria included chronic heart failure, unstable angina pectoris, anamnesis or presence of other disease with the expected survival prognosis of less than three years, presence of hemodynamically significant aortic or mitral heart defects, significant obstruction of the outflow tract of the left ventricle, severe chronic lung disease, significantly limiting physical pathology or patient's unwillingness to cooperate.

The study was approved by the Ethical Committee of the University Hospital in Brno. Each patient was informed about his/her health condition, therapy options, study information, and the training programme information including necessary physical examinations. Each patient signed an informed consent prior to the inclusion into the study. The study was conducted in

Table 1. Subjects characteristics - continuous variables

\begin{tabular}{|l|c|c|c|c|}
\hline Parameter & $\begin{array}{c}\text { All } \\
(\mathrm{N}=106)\end{array}$ & $\begin{array}{c}\text { Men } \\
(\mathrm{N}=90)\end{array}$ & $\begin{array}{c}\text { Women } \\
(\mathrm{N}=16)\end{array}$ & $\mathbf{p}^{*}$ \\
\hline Age $($ years $)$ & $60.4 \pm 10.9$ & $60.3 \pm 10.9$ & $60.9 \pm 10.5$ & 0.832 \\
\hline Height $(\mathrm{cm})$ & $174.1 \pm 7.9$ & $176.2 \pm 6.4$ & $162.0 \pm 4.4$ & $<0.001$ \\
\hline Weight $(\mathrm{kg})$ & $86.6 \pm 13.0$ & $88.8 \pm 12.3$ & $74.4 \pm 10.1$ & $<0.001$ \\
\hline BMl $\left(\mathrm{kg} / \mathrm{m}^{2}\right)$ & $28.5 \pm 3.5$ & $28.6 \pm 3.4$ & $28.4 \pm 4.0$ & 0.893 \\
\hline LV EF $(\%)$ & $57.4 \pm 7.2$ & $57.1 \pm 7.3$ & $59.6 \pm 6.3$ & 0.176 \\
\hline HR $($ beats/min) & $74.2 \pm 10.3$ & $73.7 \pm 10.4$ & $76.8 \pm 9.3$ & 0.261 \\
\hline SBP $(\mathrm{mm} \mathrm{Hg})$ & $131.3 \pm 12.2$ & $132.5 \pm 11.4$ & $130.6 \pm 10.2$ & 0.534 \\
\hline DBP $(\mathrm{mm} \mathrm{Hg})$ & $82.5 \pm 8.8$ & $83.4 \pm 8.4$ & $81.6 \pm 7.8$ & 0.427 \\
\hline
\end{tabular}

$\mathrm{N}$ - number of subjects, BMI - body mass index, LV EF - left ventricular ejection fraction, HR - heart rate, SBP - systolic blood pressure, DBP - diastolic blood pressure Mean, standard deviation, * Student's t-test

Table 2. Subjects characteristics - categorical variables - the absolute number (percentage)

\begin{tabular}{|l|c|c|c|c|}
\hline \multirow{2}{*}{ Parameter } & $\begin{array}{c}\text { All } \\
(\mathrm{N}=106)\end{array}$ & $\begin{array}{c}\text { Men } \\
(\mathbf{N}=90)\end{array}$ & $\begin{array}{c}\text { Women } \\
(\mathbf{N}=16)\end{array}$ & $\mathbf{n}(\%)$ \\
\cline { 2 - 4 } & $\mathrm{n}(\%)$ & $\mathrm{n}(\%)$ & $8(50.0)$ & 0.272 \\
\hline Patients after myocardial infarction of anterior wall & $40(37.7)$ & $32(35.6)$ & $8(50.0)$ & 0.805 \\
\hline Patients after myocardial infarction of bottom wall & $56(52.8)$ & $48(53.3)$ & $0(0.0)$ & 0.547 \\
\hline Patients with minimal myocardial lesions & $2(1.9)$ & $2(1.9)$ & $0(0.0)$ & 0.215 \\
\hline Patiens with unstable angina pectoris & $8(7.5)$ & $8(7.5)$ & $14(87.5)$ & 0.416 \\
\hline Percutaneous coronary intervention & $98(92.5)$ & $84(93.3)$ & $0(0.0)$ & 0.459 \\
\hline Coronary artery bypass graft & $3(2.8)$ & $3(2.8)$ & $2(12.5)$ & 0.111 \\
\hline Cons. treatment & $5(4.7)$ & $3(2.8)$ & $1(6.3)$ & 0.247 \\
\hline Type 2 diabetes mellitus & $17(16.0)$ & $16(17.8)$ & $9(56.3)$ & 0.956 \\
\hline Hypertension & $59(55.7)$ & $50(55.6)$ & $11(68.8)$ & 0.433 \\
\hline Hyperlipoproteinemia & $81(76.4)$ & $70(77.8)$ & $0(0.0)$ & - \\
\hline Chronic obstructive pulmonary disease & $0(0.0)$ & $0(0.0)$ & \\
\hline
\end{tabular}

$\mathrm{N}$ - number of subjects, ${ }^{*} \mathrm{X}$-square test 
accordance with the ethical standards of the Helsinki Declaration from 2000.

Selected patients experienced an acute myocardial infarction of the anterior wall (MI AW), acute myocardial infarction of the bottom wall (MI BW), with minimal myocardial lesions (MML) and unstable angina pectoris (UAP) who underwent percutaneous coronary intervention (PCI), coronary artery bypass grafting (CABG), or a conservative course of treatment was chosen.

The time passed from the occurrence of an acute coronary event (unstable angina pectoris or acute myocardial infarction) to the enrollment into the training programme was $35 \pm 8$ days, for patients after coronary artery bypass $50 \pm 16$ days.

All patients were treated with beta-blockers, ACE inhibitors or ARBs, statins, and dual antiplatelet therapy. Medical therapy was not altered during the interventional training programme.

\section{Procedures}

All subjects underwent a clinical examination and basic stress test using spiroergometry (Oxycon Delta) both prior to the enrollment and after a successful completion of the interventional training programme. A symptom-limited ramp test was performed with continuously increasing load by about $20 \mathrm{~W}$ each minute up to subject's subjective maximum or until symptoms manifestation. The value of peak oxygen consumption $\left(\mathrm{pVO}_{2}\right)$ was set to evaluate the training effect. The value of anaerobic threshold (ANP) was set to determine the training zone heart rate.

The value of the left ventricular ejection fraction was determined prior to the enrollment into the programme using transthoracic echocardiography (GE Healthcare, Vivid 7 MS4 probe, using standard projections). In order to calculate the value of left ventricular ejection fraction, the Simpson's rule was used.

The modified interventional cardiovascular rehabilitation programme took place at the Department of Internal Cardiology of the University Hospital in Brno in a form of guided training programme as a part of the second stage of CRP. The programme complied with the criteria recommended for rehabilitation of patients with cardiovascular diseases issued by the Czech Society of Cardiology in 2006. The duration of the programme was set to eight weeks in total with a frequency of three training units per week (1). The training unit was modified by extending the aerobic phase and by including a training set on treadmill. The unit's length was set to 100 minutes and consisted of several stages: warm-up phase to prevent musculoskeletal injury (15 minutes); aerobic training on the ergometer (GE Healthcare, eBike Basic ergometer); treadmill (GE Healthcare, Trackmaster X425); and rowing simulator (Concept II indoor rower) in the length of 60 minutes followed by a resistance training with the use of exercise equipment (TK-HC Compact) for the maximum length of 10 minutes. A 15 minutes long cool-down phase took place at the end of the training unit as a preventive measure to reduce the risk of arrhythmias and hypotension. During the training, patient's blood pressure and heart rate were regularly measured and subjective feelings of patients were monitored.

The acquired data were analyzed using the statistical software Statistica 10. A basic description of the data was performed using common statistical methods. Average values and standard deviation were used to describe the data set. As the first step, the normality of value distribution of the set was verified (Lilliefors modification of the Kolmogorov-Smirnov test for normality). The differences in values of monitored parameters measured prior to the training and after completing the training were evaluated by a non-parametric dependent t-test for paired samples. The differences in values of monitored parameters between men and women were evaluated by the Mann-Whitney test. To assess the influence of age on the monitored parameters, a correlation analysis between age and individual parameters was performed (Spearman correlation coefficient, R). In order to assess the possibility of individualization of the training in relation to age, patients were divided into five age groups: $30-39,40-49,50-59$, 60-69, and 70-79 years. ANOVA test was used to determine the difference in the values of monitored parameters between different age groups and to determine whether a given parameter characterizes this age group.

\section{RESULTS}

The decreased values of resting heart rate (HR) and resting systolic (SBP) and diastolic (DBP) blood pressures were observed in subjects after completing the interventional training programme. However, the measured changes did not reach a statistical significance.

A significant difference was found in values of exercise tolerance (ET), peak oxygen consumption $\left(\mathrm{pVO}_{2}\right)$, energy expenditure (EE), and anaerobic threshold (AT) measured prior to the enrollment and after completing the training programme in all subjects. The values of measured parameters increased significantly after finishing the training programme (Table 3).

A significant correlation between age and average values of monitored parameters was found (Table 4). Despite the fact that with increasing age the parameter values decrease, after finishing the training, a shift in all parameters to higher values was observed in the whole set of subjects.

A significant difference between age groups of 30-39, 40-49, $50-59,60-69$, and 70-79 years was found in most of the monitored parameters (Table 5). It was found that dispersion of the values measured within each age group is smaller than the range of values within the entire data set. This finding indicates that a parameter could characterize a certain age group.

\section{DISCUSSION}

The division of subjects into age groups showed that different age groups are more or less characterized by a certain range of parameter values. This means that variability of some parameters within each age group is smaller than variability of parameters in the entire set of subjects. During the training, however, changes in the variance of monitored parameter values occure for each age group and each parameter at a different time point. The most significant increase in variance of parameters, which means a greater impact of the training, can be observed in younger and middle aged groups. This fact could be utilized to further individualize the training including the use of various training modalities. The main training modalities include continuous and interval aerobic training. Studies comparing the effect of interval and continuous training $(6,7)$ have come to conclusion that interval training has 
Table 3. Stress parameters during training - all subjects

\begin{tabular}{|c|c|c|c|}
\hline Parameter & Pre & Post & $\mathrm{p}^{*}$ \\
\hline Systolic blood pressure (mm Hg) & $131.3 \pm 12.2$ & $130.0 \pm 11.5$ & 0.068 \\
\hline Diastolic blood pressure $(\mathrm{mm} \mathrm{Hg})$ & $82.5 \pm 8.8$ & $81.2 \pm 7.4$ & 0.075 \\
\hline Heart rate (beats/min) & $74.2 \pm 10.3$ & $73.7 \pm 11.2$ & 0.064 \\
\hline Exercise tolerance $(\mathrm{W} / \mathrm{kg})$ & $1.8 \pm 0.3$ & $2.0 \pm 0.4$ & $<0.001$ \\
\hline Peak oxygen consumption (ml/kg/min) & $22.8 \pm 4.5$ & $25.7 \pm 5.5$ & $<0.001$ \\
\hline Energy expenditure (MET) & $6.5 \pm 1.3$ & $7.4 \pm 1.6$ & $<0.001$ \\
\hline Anaerobic threshold (W) & $109.5 \pm 28.3$ & $120.1 \pm 35.0$ & $<0.001$ \\
\hline
\end{tabular}

Mean, standard deviation, *Wilcoxon nonparametric t-test

Table 4. Correlation between age and average values of monitored parameters

\begin{tabular}{|l|l|c|c|}
\hline Parameter & Units & Value & $\mathbf{R}$ \\
\hline $\mathrm{BMI}_{\text {pre }}$ & $\mathrm{kg} / \mathrm{m}^{2}$ & $28.53 \pm 3.52$ & $-0.20^{*}$ \\
\hline $\mathrm{BM}_{\text {post }}$ & $\mathrm{kg} / \mathrm{m}^{2}$ & $28.41 \pm 3.58$ & $-0.19^{*}$ \\
\hline $\mathrm{HRr}_{\text {pre }}$ & beats/min & $74.15 \pm 10.34$ & $-0.36^{* * *}$ \\
\hline $\mathrm{HRr}_{\text {post }}$ & beats/min & $73.67 \pm 11.25$ & $-0.32^{* *}$ \\
\hline $\mathrm{ET}_{\text {pre }}$ & $\mathrm{W} / \mathrm{kg}$ & $1.75 \pm 0.35$ & $-0.28^{* * *}$ \\
\hline $\mathrm{ET}_{\text {post }}$ & $\mathrm{W} / \mathrm{kg}$ & $1.99 \pm 0.43$ & $-0.36^{* * *}$ \\
\hline $\mathrm{pVO}_{2 \text { pre }}$ & $\mathrm{m} / \mathrm{kg} / \mathrm{min}$ & $22.83 \pm 4.48$ & $-0.28^{* *}$ \\
\hline $\mathrm{pVO}_{2 \text { post }}$ & $\mathrm{m} / \mathrm{kg} / \mathrm{min}$ & $25.86 \pm 5.46$ & $-0.36^{* *}$ \\
\hline $\mathrm{EE}_{\text {pre }}$ & $\mathrm{MET}$ & $6.52 \pm 1.28$ & $-0.28^{* * *}$ \\
\hline $\mathrm{EE}_{\text {post }}$ & $\mathrm{MET}$ & $7.39 \pm 1.56$ & $-0.36^{* * *}$ \\
\hline $\mathrm{AT}_{\text {pre }}$ & $\mathrm{W}$ & $109.52 \pm 28.29$ & $-0.24^{*}$ \\
\hline $\mathrm{AT}_{\text {post }}$ & $\mathrm{W}$ & $120.10 \pm 34.95$ & $-0.56^{* * *}$ \\
\hline
\end{tabular}

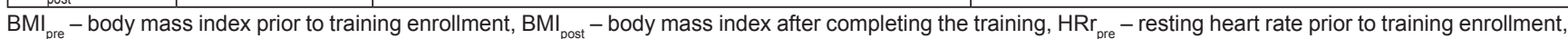

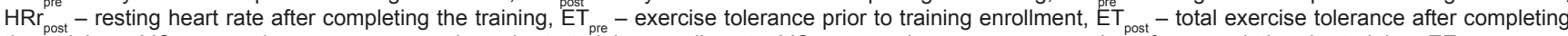
the training, $\mathrm{pVO}_{2 \text { re }}$ - peak oxygen consumption prior to training enrollment, $\mathrm{pVO}_{2 \text { ost }}$ - peak oxygen consumption after completing the training, $\mathrm{EE}_{\mathrm{pre}}-\mathrm{energy}$ expenditure prior to training enrollment, $\mathrm{EE}_{\text {post }}$ - energy expenditure after completing the training, $\mathrm{AT}_{\text {pre }}$ - maximum power at anaerobic threshold prior to training enrollment, $\mathrm{AT}_{\text {post }}$ - maximum power at anaerobic threshold after completing the training

Mean, standard deviation; $R$, Spearman's correlation coefficient (correlation between age and average values); ${ }^{* * *} p<0.001,{ }^{* *} p<0.01,{ }^{*} p<0.05$

a comparatively greater effect on improving cardiorespiratory and certain biochemical indicators that are directly related to cardiovascular diseases risk factors. Interval training is more suitable for the elderly patients due to the starting lower value of aerobic capacity and higher incidence of physical pathologies which can be a limitation of training. On the contrary, in younger patients, it is possible to indicate higher intensity of exercise and choose a larger variability in the use of exercise equipment (e.g. prevailing share of treadmill or rowing simulator use), all in compliance with the safe load limits for the cardiovascular system.

With increasing age, the values of all parameters are dropping. After completing the training cycle, a shift towards higher parameter values was observed causing also the correlation line to reach higher levels for the whole data set. This fact can be utilized when deciding an appropriate prescription of physical activity for elderly patients over 65 years of age. These patients can positively affect their physical condition by completing the interventional training programme $(8,9)$.

In the future, it will be necessary to conduct further studies repeatedly measuring parameters of individuals in order to perform a statistical analysis between individuals instead of groups to be able to determine whether the intra-individual variability is smaller than inter-individual and therefore the parameter char- acterizes an individual. It would be also appropriate to assess the correlation of individual averages from several measurements of individual persons with the variation of their values.

The results of the study also point to a significant improvement in cardiorespiratory indicators and indicators of exercise tolerance after completing the training which is crucial in relation to the risk factors for coronary artery disease (CAD). Long-term and systematic aerobic exercise has a positive effect on hypertension, diabetes mellitus, dyslipidemia and abdominal obesity (10-14).

Regular exercise positively affects the functional capacity of the organism by reducing resting and stress HR, reducing blood pressure, and increasing venous tone. It also leads to improvement of myocardial contractility (15-19). As far as hemodynamics is concerned, a trend of decreasing resting heart rate and systolic as well as diastolic blood pressure was indicated after completing the training programme.

Despite the fact that the study subjects had a relatively good initial aerobic capacity, the training improved it even further. Taking into account that the peak oxygen consumption is considered to be one of the most significant prognostic factors in patients with CAD (20-22) and that its improvement of $1 \mathrm{ml} / \mathrm{kg} / \mathrm{min}$ is related to a $9-10 \%$ reduction in cardiovascular mortality $(19,20)$, a decrease in cardiovascular mortality in subjects of the study by 
Table 5. Difference in the monitored parameters between age groups 1 (30-39), 2 (40-49), 3 (50-59), 4 (60-69), and 5 (70-79 years)

\begin{tabular}{|l|c|c|c|c|c|c|c|}
\hline Parameter & Units & $\begin{array}{c}\text { Group 1 } \\
(\mathbf{n}=10)\end{array}$ & $\begin{array}{c}\text { Group 2 } \\
(\mathbf{n}=10)\end{array}$ & $\begin{array}{c}\text { Group 3 } \\
(\mathbf{n = 2 2})\end{array}$ & $\begin{array}{c}\text { Group 4 } \\
(\mathbf{n = 4 7})\end{array}$ & $\begin{array}{c}\text { Group 5 } \\
(\mathbf{n}=17)\end{array}$ & $\mathrm{F}$ \\
\hline $\mathrm{BM}_{\text {pre }}$ & $\mathrm{kg} / \mathrm{m}^{2}$ & $31.62 \pm 5.46$ & $28.26 \pm 3.18$ & $28.79 \pm 3.59$ & $28.61 \pm 3.30$ & $26.59 \pm 2.25$ & $2.71^{*}$ \\
\hline $\mathrm{BM}_{\text {post }}$ & $\mathrm{kg} / \mathrm{m}^{2}$ & $32.01 \pm 6.26$ & $28.07 \pm 3.17$ & $28.59 \pm 3.51$ & $28.49 \pm 3.24$ & $26.49 \pm 2.23$ & $3.13^{*}$ \\
\hline $\mathrm{HR}_{\text {pre }}$ & beats/min & $81.71 \pm 8.28$ & $80.77 \pm 8.85$ & $75.30 \pm 8.33$ & $73.05 \pm 10.92$ & $66.07 \pm 8.07$ & $5.60^{* * *}$ \\
\hline $\mathrm{HR}_{\text {post }}$ & beats/min & $85.43 \pm 5.41$ & $77.00 \pm 9.49$ & $73.26 \pm 8.40$ & $73.34 \pm 12.82$ & $67.00 \pm 9.80$ & $3.93^{*}$ \\
\hline $\mathrm{ET}_{\text {pre }}$ & $\mathrm{W} / \mathrm{kg}$ & $1.83 \pm 0.33$ & $1.95 \pm 0.36$ & $1.87 \pm 0.35$ & $1.66 \pm 0.29$ & $1.64 \pm 0.36$ & $3.44^{* *}$ \\
\hline $\mathrm{ET}_{\text {post }}$ & $\mathrm{W} / \mathrm{kg}$ & $2.29 \pm 0.75$ & $2.19 \pm 0.30$ & $2,09 \pm 0.39$ & $1.89 \pm 0.38$ & $1.79 \pm 0.33$ & $3.91^{* *}$ \\
\hline $\mathrm{pVO}_{2 \text { pre }}$ & $\mathrm{ml} / \mathrm{kg} / \mathrm{min}$ & $23.83 \pm 4.24$ & $25.40 \pm 4.72$ & $24.25 \pm 4.56$ & $21.55 \pm 3.80$ & $21.35 \pm 4.74$ & $3.44^{* *}$ \\
\hline $\mathrm{pVO}_{2 \text { post }}$ & $\mathrm{ml} / \mathrm{kg} / \mathrm{min}$ & $29.83 \pm 9.70$ & $28.48 \pm 3.90$ & $27.14 \pm 5.01$ & $24.57 \pm 4.98$ & $23.23 \pm 4.23$ & $3.91^{* *}$ \\
\hline $\mathrm{EE}_{\text {pre }}$ & $\mathrm{MET}$ & $6.81 \pm 1.21$ & $7.26 \pm 1.35$ & $6.93 \pm 1.30$ & $6.16 \pm 1.09$ & $6.10 \pm 1.36$ & $3.44^{* *}$ \\
\hline $\mathrm{EE}_{\text {post }}$ & $\mathrm{MET}$ & $8.52 \pm 2.77$ & $8.14 \pm 1.11$ & $7.75 \pm 1.43$ & $7.02 \pm 1.42$ & $6.64 \pm 1.21$ & $3.91^{* *}$ \\
\hline $\mathrm{AT}_{\text {pre }}$ & $\mathrm{W}$ & $88.33 \pm 14.43$ & $137.11 \pm 28.86$ & $116.11 \pm 30.61$ & $102.35 \pm 22.83$ & $98.91 \pm 22.83$ & $4.34^{* *}$ \\
\hline $\mathrm{AT}_{\text {post }}$ & $\mathrm{W}$ & $149.33 \pm 30.02$ & $159.89 \pm 24.00$ & $132.47 \pm 36.99$ & $105.85 \pm 23.33$ & $93.18 \pm 21.74$ & $10.64^{* * *}$ \\
\hline
\end{tabular}

$\mathrm{BMI}_{\text {pre }}$ - body mass index prior to training enrollment, $\mathrm{BMI}_{\text {post }}$ - body mass index after completing the training, $\mathrm{HRr}_{\text {pre }}-\mathrm{resting}_{\mathrm{n}}$ heart rate prior to training enrollment $\mathrm{HRr}^{\mathrm{pre}}$-resting heartrate aftercompleting the training, $\mathrm{ET}_{\text {pre }}$ - exercise tolerance prior to training enrollment, $\mathrm{ET}_{\text {post }}$-total exercise tolerance aftercompleting the training, $\mathrm{pVO}_{2 \mathrm{pre}}-$ peakoxygen consumption prior to training enrollment, $\mathrm{pVO}_{2 \text { post }}$ - peak oxygen consumption after completing the training, $\mathrm{EE}_{\text {pre }}$-energy expenditure prior to training enrollment, $\mathrm{EE}_{\text {post }}$-energy ex-

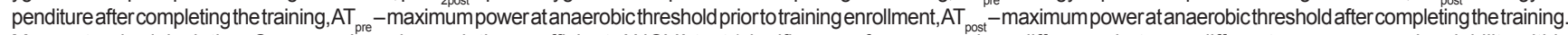
Mean, standard deviation; Spearman's rank correlation coefficient, ANOVA test (significance of average values difference between different age groups and variability within each age group and variability within the entire set; ${ }^{* *} p<0.001,{ }^{* *} p<0.01,{ }^{*} p<0.05$

about $30 \%$ can be expected. Another positive fact is that according to Kavanagh et al., an improvement in peak oxygen consumption greater than $22 \mathrm{ml} / \mathrm{kg} / \mathrm{min}$ reduces the risk of cardiovascular death by up to $61 \%(20)$. The presented values have been achieved in the study on average in men as well as in women.

The main goals of cardiac rehabilitation include encouraging patient's positive attitude towards physical activity with sufficiently strong motivation for a long-term individual exercise. In the study comparing controlled and uncontrolled aerobic training among cardiac patients an improvement in exercise parameters of groups training intensively and consistently at home was observed. On the other hand, worsening parameters were observed in groups of patients exercising at home uncontrolled, regardless of a completion of the initial ambulatory rehabilitation programme (23-25). From the psychological point of view, cardiovascular rehabilitation has a positive effect on patients. It restores their lost confidence, relieves them from fear of a physical load, allows them to return back into active life and eliminates a serious risk factor - physical inactivity.

\section{CONCLUSION}

The study showed some important connections that can be utilized for the practical application of aerobic-resistance training prescription for patients with CAD. There are interindividual differences between certain parameters that could help in methodological planning of preventive training programmes for patients with cardiovascular diseases. Their correlation with age groups is not only related to a safe determination of the training intensity, but also to better targeted application of various training modalities in order to achieve optimal training effect. Significant improvement in cardiorespiratory indicators and indicators of exercise tolerance after completing the modified interventional training programme reinforces the crucial role of physical activity in CRP and the positive influence on risk factors of CAD which can lead to improved prognosis of such patients. Cardiovascular rehabilitation should therefore be a common part of the secondary and tertiary preventive procedures for patients after acute coronary event.

\section{REFERENCES}

1. Chaloupka V, Siegelová J, Špinarová L, Skalická H, Karel I, Leisser J. Rehabilitation in patiens with cardiovascular diseases. Cor et Vasa. 2006; 48(7-8):K127-45. (In Czech.)

2. Gupta R, Sanderson BK, Bittner V. Outcomes at one-year follow-up of women and men with coronary artery disease discharged from cardiac rehabilitation: what benefits are maintained? J Cardiopulm Rehabil Prev. 2007 Jan-Feb;27(1):11-8.

3. Chaloupka V, Elbl L. Rehabilitation after myocardial infarction. Kardiol Rev Int Med. 2005; 7(1):5-9. (In Czech.)

4. Chaloupka V, Elbl L. Rehabilitation after myocardial infarction (II): workload methods. Kardiol Rev Int Med. 2005; 7(2):73-6. (In Czech.)

5. Chaloupka V, Elbl L. Rehabilitation after myocardial infarction (III). Kardiol Rev Int Med. 2005; 7(4):187-90. (In Czech.)

6. Tjønna AE, Lee SJ, Rognmo Ø, Stølen TO, Bye A, Haram PM, et al. Aerobic interval training versus continuous moderate exercise as a treatment for the metabolic syndrome: a pilot study. Circulation. 2008 Jul 22;118(4):346-54.

7. Pattyn N, Coeckelberghs E, Buys R, Cornelissen VA, Vanhees L. Aerobic interval training vs. moderate continuous training in coronary artery disease patients: a systematic review and meta-analysis. Sports Med. 2014 May;44(5):687-700.

8. Hollenberg M, Yang J, Haight TJ, Tager IB. Longitudinal changes in aerobic capacity: implications for concepts of aging. J Gerontol A Biol Sci Med Sci. 2006 Aug;61(8):851-8.

9. Sousa N, Mendes R, Abrantes C, Sampaio J, Oliveira J. Effectiveness of combined exercise training to improve functional fitness in older adults: A randomized controlled trial. Geriatr Gerontol Int. 2014 Oct;14(4):892-8.

10. Máček M, Máčková J. The need of physical activity in advanced age. Med Sport Boh Slov. 2008; 17(1):34-42. (In Czech.) 
11. Fagard RH, Cornelissen VA. Effect of exercise on blood pressure control in hypertensive patients. Eur J Cardiovasc Prev Rehabil. 2007 Feb;14(1):12-17.

12. Boulé NG, Haddad E, Kenny GP, Wells GA, Sigal RJ. Effects of exercise on glycemic control and body mass in type 2 diabetes mellitus: a metaanalysis of controlled clinical trials. JAMA. 2001 Sep 12;286(10):121827.

13. Kodama S, Tanaka S, Saito K, Shu M, Sone Y, Onitake F, et al. Effect of aerobic exercise training on serum levels of high-density lipoprotein cholesterol: a meta-analysis. Arch Intern Med. 2007 May 28;167(10):9991008 .

14. Kelley GA, Kelley KS, Franklin B. Aerobic exercise and lipids and lipoproteins in patients with cardiovascular disease: a meta-analysis of randomized controlled trials. J Cardiopulm Rehabil. 2006 MayJun;26(3):131-9.

15. Elbl L, Chaloupka V, Nehyba S, Tomášková I, Kala P, Schildberger J, et al. The importance of combined rehabilitation programme in patients with chronic ischaemic heart disease. Vnitř Lék. 2005; 51(9):957-64. (In Czech.)

16. Elbl L, Chaloupka V, Tomášková I, Jedlička F, Nehyba S, Kala P, et al. The influence of combined aerobic and resistance training on left ventricle function in patients after acute myocardial infarction. Vnitř Lék. 2005; 51(2):190-7. (In Czech.)

17. Jančík J, Svačinová H, Dobšák P, Siegelová J, Placheta Z, Meluzín J, et al. Combined training in patients with systolic dysfunction of the left ventricle. Vnitř Lék. 2003; 49(4):280-4. (In Czech.)

18. Elbl L, Chaloupka V, Nehyba S, Tomášková I, Jedlička F, Kala P, et al. The influence of the combined aerobic training to the changes of autonomous modulation at the ill patients after the acute myocardial infarction. Vnitř Lék. 2005; 51(4):421-9. (In Czech.)
19. Kavanagh T, Mertens DJ, Hamm LF, Beyene J, Kennedy J, Corey P, et al. Peak oxygen intake and cardiac mortality in women referred for cardiac rehabilitation. J Am Coll Cardiol. 2003 Dec 17;42(12):2139-43.

20. Kavanagh T, Mertens DJ, Hamm LF, Beyene J, Kennedy J, Corey P, et al. Prediction of long-term prognosis in 12169 men referred for cardiac rehabilitation. Circulation. 2002 Aug 6;106(6):666-71.

21. Myers J, Prakash M, Froelicher V, Do D, Partington S, Atwood JE. Exercise capacity and mortality among men referred for exercise testing. N Engl J Med. 2002 Mar 14;346(11):793-801.

22. Ades PA, Savage PD, Brawner CA, Lyon CE, Ehrman JK, Bunn JY, et al. Aerobic capacity in patients entering cardiac rehabilitation. Circulation. 2006 Jun 13;113(23):2706-12.

23. Panovský R, Jančár R, Meluzín J, Jančík J, Kožantová L, Mífková L, et al.: Comparison of controlled and uncoltrolled aerobic physical training of patients with chronic coronary heart disease. Kardiol Rev Int Med. 2005; 7(2): 67-72. (In Czech.)

24. Magalhães S, Viamonte S, Miguel Ribeiro M, Barreira A, Fernandes $\mathrm{P}$, Torres $\mathrm{S}$, et al. Long-term effects of a cardiac rehabilitation program in the control of cardiovascular risk factors. Rev Port Cardiol. 2013 Mar;32(3):191-9. (In Portugal.)

25. Lavie CJ, Milani RV. Cardiac rehabilitation and exercise training in secondary coronary heart disease prevention. Prog Cardiovasc Dis. 2011 May-Jun;53(6):397-403.

Received September 2, 2014 Accepted in revised form May 16, 2015 